\title{
REMANESCENTES PAISAGÍSTICOS DA CIDADE MODERNA: \\ apoteose e decadência do Parque Centenário, em Criciúma/SC
}

REMINISCENCES LANDSCAPES OF THE MODERN CITY: apotheoses and decadence of the Parque Centenário, in Criciúma/SC

\author{
Gustavo Rogério De Lucca A, B, C, D, E, F \\ Universidade Federal de Santa Catarina, Programa de Pós-Graduação em Geografia, Florianópolis, SC, Brasil \\ Margareth de Castro Afeche Pimenta A, D, e, F \\ Universidade Federal de Santa Catarina, Departamento de Arquitetura e Urbanismo, Florianópolis, SC, Brasil
}

\begin{abstract}
R E S U M O : A industrialização brasileira em meados do século XX estimulou profundas transformações nas paisagens urbanas, constituindo dimensôes inéditas para as novas estruturas de circulação e de uso público. Nesse processo, investimentos estatais deram forma a novos espaços abertos que, não raro, reorganizavam o tecido urbano e se inseriam nas cidades como signos de desenvolvimento. Como herança à cidade contemporânea, essa geração de áreas públicas se constitui em um mosaico de referências históricas do urbanismo brasileiro, mas também em um desafio para um país que ainda pouco reconhece seu patrimônio moderno. Na qualidade de objeto de estudo deste artigo, discutem-se as inserçôes do Parque Centenário - complexo modernista das décadas de 1970 e 80, mas já condenado por descaracterizaçôes diversas - nos imaginários e na estrutura urbana de Criciúma, importante cidade industrial catarinense. Considera-se que o seu reconhecimento como uma das principais obras públicas do modernismo no interior do país permeia quaisquer novas possibilidades para sua preservação.
\end{abstract}

P A L A V R A S - C H A V E : espaços públicos; paisagens históricas; modernismo; Criciúma; Parque Centenário.

A B S T R A C T: Brazilian industrialization in the middle of the twentieth century stimulated profound transformations in urban landscapes and constituted unprecedented dimensions for new structures of circulation and public use. In this process, state investments render possible the creation of new open spaces that often reorganized the urban fabric and inserted themselves into the cities as signs of development. As a heritage to the contemporary city, this generation of public areas is a mosaic of historical references to Brazilian urbanism, but also a challenge for a country that still has little recognition of its modern heritage. As an object of study of this article, we discuss the insertions of Parque Centenário - modernist complex of the 1970s and 80s, but already condemned by various decharacterizations - in the imaginary and urban structure of Criciuma, an important industrial city in Santa Catarina, Brazil. Its recognition as one of the main public works of modernism in the countryside of the country is considered to be a way to permeate any new possibilities for its preservation.

KEYWORDS: public spaces; historical landscapes; modernism; Criciúma; Parque Centenário.

Contribuição de cada autor/a: A. fundamentação teórico-conceitual e problematização; B. pesquisa de dados e análise estatística; C. elaboração de figuras e tabelas; D. fotos; E. elaboração e redação do texto; F. seleção das referências bibliográficas. DOI: https://doi.org/10.22296/2317-1529.2018v20n1p85 


\section{INTRODUÇÃO}

Uma avaliação do processo de urbanização no Brasil possibilita identificar dinâmicas socioespaciais que, associadas a intervençôes de Estado, legaram às cidades espaços públicos que nasceram como protagonistas das paisagens. Para essas dinâmicas, ainda que possam haver exemplos nas reformas urbanas nas áreas centrais no período da Primeira República, é evidente o protagonismo do movimento moderno da segunda metade do século XX na consolidação de ambiçóes urbanísticas através da implantação de novas dimensôes para o uso público, coexistentes à construção de um país - e de cidades - também com aspiraçôes industriais e modernas. Assim, especialmente entre as décadas de 1950 e 1980, acompanhadas de significativo aumento populacional, novas tecnologias de comunicação e mobilidade rompiam com a escala humanizada típica dos núcleos urbanos e incentivavam seu espraiamento. Simultaneamente à vigência da linguagem modernista, eram realizadas intervençôes nas áreas centrais e implantadas áreas verdes de tamanho expressivo em alguns dos novos bairros residenciais que surgiam nas grandes e médias cidades do país. Através de intervençôes de grande impacto, geralmente associadas a nomes prestigiados da arquitetura e do paisagismo, importantes espaços públicos tomavam forma e se consolidavam como novos símbolos urbanos, alguns até hoje considerados verdadeiros conjuntos paisagísticos e representativos da atuação do Estado. Guardadas particularidades e contextos, são exemplos dessa prática o Parque do Ibirapuera, de 1954, em Sáo Paulo, que mescla o modernismo de Oscar Niemeyer com o simples, mas pitoresco, projeto paisagístico de Otávio Augusto Teixeira Mendes, notório profissional de sua época; o Parque do Flamengo, de 1965, no Rio de Janeiro, com desenho do mestre paisagista Roberto Burle Marx; e, em Florianópolis, dos anos 1970, o Parque Metropolitano, também de Burle Marx, mas abandonado já nos primeiros anos e nunca plenamente concretizado (MACEDO; SAKATA, 2003). Junto a outros espaços espalhados por capitais e cidades menores - e, por isso, ainda pouco conhecidos - forma-se um mosaico de experiências de vanguarda, verdadeiros documentos da história da urbanização moderna no país.

Com sua escala e especificidades, Criciúma, polo de uma rica região extrativista e industrial catarinense, incorporou as formas modernas como parte de um processo de transformaçóes socioeconômicas e urbanas que marcaram as décadas de 1960, 70 e 80 . Num primeiro momento, a escala humanizada das praças centrais e jardins envoltos por edifícios públicos definiam com legibilidade uma trama de espaços que configuravam a centralidade histórica da cidade mineradora, cujas origens remetem ao fim do século XIX. Na segunda metade do século XX, acompanhando os processos de urbanizaçáo no país, as escalas mudam, a economia local incorpora novas atividades industriais e a cidade é parcialmente renovada; espraia-se por intermédio da implantação de vias arteriais e de ligações regionais, ao mesmo tempo em que são construídos ou ampliados espaços públicos no Centro e nos principais bairros periféricos. Nessa ambiência de expansão e de robustas intervençóes estatais é implantado o Parque Centenário, ícone da urbanização modernista, que concretizou as ambiçôes administrativas e os imaginários mais importantes de sua época. Representou, no alvorecer da década de 1980, a construção de equipamentos cívicos, culturais e esportivos que se consolidaram como os novos símbolos de uma cidade em transformação: uma sala de espetáculos de grande porte, uma biblioteca pública confortável, 
uma galeria de arte, além de novos espaços esportivos e administrativos - referências arquitetônicas de qualidade para além das capitais e das maiores cidades do país.

$\mathrm{Na}$ história da urbanização brasileira, grandes mudanças econômicas e político-administrativas comumente fragilizaram a condição de continuidade, tão necessária para a conclusão do inacabado, para valorização de obras públicas do passado e sua conciliação com as demandas recentes. Nesse sentido, a ascensão neoliberal no limiar do século XXI e a escolha por uma sociedade de consumidores (SANTOS, 2014) contribuíram para que setores hegemônicos de capitais assumissem, de fato, o papel de principais agentes nos processos de planejamento. E, se por um lado houve retrocessos na atuação do Estado como promotor de grandes estruturas de uso público, por outro, multiplicaram-se ambientes privados segregados e até mesmo mutilaçôes de espaços que a cidade já produziu em outras épocas. Em Criciúma, sob influências da crise brasileira da segunda metade dos anos 1980, agravada por açôes neoliberais violentas no início dos anos 1990, a insuficiência de investimentos e certo desinteresse administrativo tornaram cada vez mais difíceis a manutenção e a preservação dos espaços públicos modernos, inclusive o Parque Centenário, o mais significativo para a cidade.

Diante de seu retrato atual, este artigo debate e resgata a história do Parque Centenário como exemplo de um processo de desmanche de uma importante - e pouco conhecida - referência do movimento moderno no interior do país. Além disso, analisa os diferentes aspectos que caracterizam sua arquitetura, sua inserção na estrutura da cidade e seu valor simbólico para a população. A crítica às condiçôes atuais de decadência do Parque Centenário é uma possibilidade de se debater a importância e as perspectivas desses espaços herdados do Brasil moderno, e também para chamar atenção para a importância de preservá-los. No cenário local, especula-se que o comprometimento real da academia e de outras instâncias da sociedade pode ser um catalisador de açôes políticas que visem a solucionar seus problemas estruturais e a torná-lo, de fato, uma alegoria do reconhecimento coletivo do direito à cidade.

\section{QUESTÃO DE CONTEXTO: A PRESERVAÇÃO DOS CONJUNTOS PAISAGÍSTICOS PÚBLICOS NO BRASIL}

As paisagens urbanas constituem em si a própria essência das cidades. Interaçóes do homem com o território em épocas diversas e que resultam em variaçóes localizadas do mundo como extratos da história das sociedades: sua organização espacial, suas riquezas e seus dilemas, suas utopias e seus projetos não realizados. Além disso, as paisagens do presente, ainda que acumulem elementos herdados do passado, são também representativas da sociedade atual. Se conjuntos ou imóveis históricos são preservados ou demolidos, se há ou não preocupação pela conciliação harmônica de novas formas, se há apreço pelos bens públicos ou até mesmo se há reverência pelos espaços lúdicos, coletivos e de interação social, tudo isso tem muito a revelar sobre os valores cultivados no cotidiano.

Assim, quando a cidade é conduzida primordialmente por interesses econômicos, a solidariedade que faz reconhecer os bens públicos ou os bens históricos como direito do outro se torna frágil ou até mesmo inexistente. "Deixado ao quase exclusivo jogo do 
mercado, o espaço vivido consagra desigualdades e injustiças e termina por ser, em sua maior parte, um espaço sem cidadãos” (SANTOS, 2014, p. 59). O resultado desse jogo é "um espaço empobrecido e que também se empobrece: material, social, política, cultural e moralmente" (SANTOS, 2014, p. 65). Tal empobrecimento pode estar além da dialética entre espaços públicos e privados; está também no desprezo ao que não interessa ao mercado. Está na indiferença ao valor de uso, ainda que seja essa a base para um real compromisso com a cidade social. Segundo Lefebvre (2001, p. 87), "a sociedade urbana, conjunto de atos que se desenrolam no tempo, privilegiando um espaço (sítio, lugar) e por ele privilegiados, altamente significantes e significados, tem uma lógica diferente da lógica da mercadoria. É um outro mundo. O urbano se baseia no valor de uso".

Do desprezo aos valores sociais, observa-se que o processo de urbanização no Brasil é pautado por movimentos expansivos pouco conciliadores, descontínuos, que impóem rupturas violentas às paisagens históricas, ao desenho urbano e ao cultivo de espaços públicos. Quando os espaços representativos de outras épocas náo são ignorados pelas novas circunstâncias econômicas ou políticas, são rapidamente descaracterizados e até mesmo eliminados como lugares de memória. Sem grandes resistências, referências arquitetônicas de épocas e estilos variados deterioram-se a níveis agonizantes. Também são comuns, dado o desapego à memória, à relevância dos bens históricos e à ausência de planejamento com caráter efetivamente social, que monumentos urbanos importantes do passado sejam descaracterizados ante às intervençôes incompatíveis, ao cultivo de movimentos privatizadores e às limitaçóes do imediatismo das gestôes municipais. À insuficiência de açôes patrimoniais verticais, que articulem e fortaleçam as diferentes escalas de governo, soma-se a fragilidade de órgãos municipais desprestigiados e tecnicamente limitados. Assim, ao contrário de países que têm tradição por preservar verdadeiros conjuntos arquitetônicos e suas inserçóes na paisagem, o que sobra por aqui é a disputa desequilibrada entre agressivos processos de fragmentação e vestígios paisagísticos que, quando plenos e dispensáveis aos interesses rentistas, convivem com o constante prenúncio do abandono.

A indiferença aos espaços públicos e aos conjuntos paisagísticos é consequência de uma sociedade que, ainda alheia à plena cidadania, abre máo da cidade social - o que inclui a memória intrínseca a essas paisagens - como direito. A realidade nacional pouco espacializa o aprimoramento do debate internacional, restringindo-se, quando muito, à obviedade da preservação de imóveis isolados. Quando se trata de conjuntos modernistas, esses dilemas se amplificam. Suas ideias de vanguarda, especialmente a partir dos anos 1940 e 1950, acompanharam e traduziram em formas um projeto de modernizaçáo das forças produtivas do país, ainda que limitadas e contraditórias. A negligência à preservação desse patrimônio dissolvido pelo país nas mais diversificadas variaçóes é um atentado às paisagens urbanas e um flerte com o desmanche de espaços que registram capítulos importantes da história das cidades brasileiras, ainda hoje insuficientemente esclarecidos.

Se o espaço é sempre carregado de sentido, "suas formas e seu traçado se remetem entre si e se articulam numa estrutura simbólica, cuja eficácia sobre as práticas sociais revela-se em toda análise concreta" (CASTELLS, 1983, p. 304). Desse modo, a compreensão do valor da herança patrimonial que configura o Parque Centenário, obra-prima do modernismo catarinense, torna-se mais clara com a investigação de seus processos. Pressupóe, ainda, uma análise das diversas escalas espaciais e suas inter-relaçôes como parte de uma totalidade. Tal esforço pela apreensão do "espírito 
do lugar", classificando os elementos do espaço, suas variaçóes e interaçóes, tende a resultar em um instrumento coerente para consideraçóes mais expressivas sobre seu futuro. Além de um objeto de análise, o Parque Centenário é a figuração localizada de um ciclo desenvolvimentista nacional já encerrado, o vestígio de um período marcado por grandes intervençóes estatais e pela construção de novos imaginários urbanos em uma cidade pobre em valores simbólicos e em espaços públicos. Enfatiza-se, portanto, que a partir de novas interaçôes, precisa cultivar-se como história e ressignificar-se na qualidade de símbolo para novas possibilidades.

\section{CRICIÚMA: DA MINERAÇÃO DE CARVÃO À CONSTRUÇÃO DA CIDADE MODERNA}

No contexto brasileiro, as interpretaçóes do urbanismo modernista difundiam-se concomitantes ao desenvolvimento da indústria nacional e à construção da imagem de uma nação moderna, gerida por um estado forte e ideologicamente desenvolvimentista. Especialmente entre as décadas de 1950 e 1980, quando o país passava por um vigoroso processo de expansão das cidades, intervençôes espaciais absolutamente impactantes eram inseridas à vida urbana como símbolos de progresso e soluçôes para conflitos cotidianos. Nessas dinâmicas, por mais que se reconheça o envolvimento do capital imobiliário especulativo ou de relaçôes públicas estritamente corporativistas e autoritárias, não se pode desconsiderar, mesmo que fosse restrito apenas a uma construção ideológica destoante da realidade, que o desenvolvimento econômico simulava no horizonte o projeto de um país moderno, a expectativa de um amanhã mais promissor.

Foi nessa ambiência que foi aplicado, à sua escala, um conjunto de experiências urbanísticas modernas para Criciúma, simultâneas ao momento de diversificação da economia local. A fundação da cidade data de 1880 e está inserida no quadro de estabelecimento de núcleos coloniais espalhados pelo território das bacias dos rios Tubarão, Urussanga e Araranguá, no Sul Catarinense. Logo que instalados, os núcleos cresceram, tornaram-se pequenas cidades e configuraram-se como uma rede urbana, ainda que completamente precária. Interligavam-se por estradas construídas pelos próprios imigrantes, as quais se convergiam ao núcleo central de Criciúma, o centro geográfico da região.

Das dificuldades de vida e de trabalho na rede urbana do fim do século XIX, o carvão mineral recém descoberto foi, gradativamente, assumindo papel de combustível para novas possibilidades econômicas e para expectativas de transformaçóes num ambiente até então agrícola e dominado por precariedades de todos os tipos. Sob as circunstâncias das duas guerras mundiais, foi através do protecionismo de Estado sobre o carvão que se construiu uma poderosa indústria extrativista que, ao longo de décadas, conduziu as dinâmicas econômicas e políticas da cidade. Conforme discursos dominantes à época, tratava-se da chegada do progresso, uma abstração ora ou outra concretizada em símbolos da industrializaçâo, tais como a locomotiva, a estação de passageiros e toda a dinâmica de urbanização a ela relacionada. Em poucos anos, Criciúma assumia a posição de maior produtora de carvão no Brasil, matéria-prima essencial para o abastecimento do parque industrial que se formava nos estados de São Paulo, Minas Gerais e Rio de Janeiro.

Consequência do momento econômico, a urbanização acelerada revelava marcas de uma sociedade desigual e de uma estrutura urbana explicitamente segregada. A 
1 O Banco Nacional da Habitação foi uma empresa pública criada em 1964 e extinta em 1986. Realizava operações de financiamento imobiliário, bem como de gestão do Fundo de Garantia do Tempo de Serviço (FGTS). massa de mineiros assalariados que crescia a cada nova chegada do trem de passageiros influenciava na expansão da malha urbana, no adensamento construtivo, na produção de localizaçóes, na construção de símbolos e imaginários, espacializando a lógica da desigualdade e as limitaçôes de políticas públicas para o equilíbrio social. Os números que registram o aumento da população urbana são expressivos: em 1940 eram 4.854 habitantes; em 1950, 9.298; e em 1960, mais de 27 mil, num universo de 61.975 habitantes no município (para 2016, estima-se uma população de 209.153 habitantes, segundo o Instituto Brasileiro de Geografia e Estatística (IBGE)).

Apesar da significativa circulação de riquezas e da sensação de progresso cotidiano que prevaleceu por décadas nos discursos e nas práticas de renovação da paisagem, o ambiente urbano por volta dos anos 1960 já se tornava representativo de uma dinâmica socioeconômica em eminente colapso. Sob a matriz econômica monopolizada, se por um lado se implantavam novas áreas residenciais à medida que se registravam recordes sucessivos na produtividade das minas, por outro, também se agravavam crises sanitárias nos bairros operários e conflitos trabalhistas com desfechos às vezes violentos.

Nos anos 1960 e 1970, quando o momento econômico do país e o advento do óleo como combustível industrial põem em discussão o horizonte da indústria carbonífera, o capital acumulado pela elite empresarial de Criciúma possibilita a condução de um inédito processo de diversificação das atividades produtivas, especializando-se, principalmente, nos revestimentos cerâmicos, setor impulsionado com a criaçáo do Banco Nacional de Habitação $(\mathrm{BNH})^{1}$ nos anos 1970 e, posteriormente, com o aumento nos financiamentos para o desenvolvimento do setor da construção civil no país (SANTOS, 1995).

Rupturas econômicas fomentam transformaçóes espaciais marcantes, pois "na medida em que a economia se altera profundamente, assim como a sociedade correspondente, e na medida também em que os tipos de relaçôes econômicas e de toda ordem mudam substancialmente, as cidades se tornam rapidamente outra coisa em relação ao que eram até então" (SANTOS, 2012, p. 64). No contexto de renovação do parque produtivo, o imaginário de progresso absorve novas formas, discursos e desejos. Estruturas ferroviárias e imagens ligadas à mineração tornam-se, aos poucos, obsoletas. Sob o autoritarismo vigente, ampliam-se escalas e renova-se a área central da cidade, em parte sob a aplicação do Plano Diretor de 1973, o primeiro da história de Criciúma, e que se aproximava dos princípios da Carta de Atenas: interligadas por corredores viários com possibilidade de adensamento, previa unidades de vizinhança com a consolidação de centralidades locais de média densidade, servidas com áreas verdes e equipamentos comunitários. Constroem-se, assim, praças e outros espaços para pedestres, edifícios públicos maiores, uma avenida estruturadora no lugar da estrada de ferro - deslocada para fora do perímetro urbano - e novas ligaçôes rodoviárias regionais. Abrem-se novos caminhos para a inserçấo do setor imobiliário que, como em todo o país, passa-se a transformar a paisagem de modo permanente através de escalas construtivas até então inexistentes. Finalmente, também previsto no Plano como um projeto especial para essa cidade modernizada e promissora, o Parque Centenário, que não se tratava da construção de um objeto isolado ou de um detalhe em um momento de grandes intervençôes públicas, mas do desfecho de um processo de renovação da paisagem; conjunto estruturador do espaço urbano e da expectativa de uma cidade que nunca aconteceria. 


\section{O PARQUE CENTENÁRIO COMO RETRATO DE UMA INTENÇÃO DE CIDADE}

A construção do Parque Centenário, entre o fim da década de 1970 e o início dos anos 1980, sintetizou em um mesmo conjunto os novos imaginários de progresso construídos, aos poucos, através da diversificação econômica, dos discursos políticos e de obras públicas que camuflaram parte das paisagens peculiares da cidade mineradora. Foi implantado como solução de uso para uma ampla área pública localizada a apenas dois quilômetros do núcleo central da cidade, até entáo ocupada pelo aeródromo municipal, cuja pista para pousos e decolagens não era pavimentada e media aproximadamente 1.600 x 70m. A transferência do aeródromo, já envolto por áreas urbanizadas em plena dinâmica de expansão, para uma área mais afastada do perímetro urbano cumpriria exigências técnicas de segurança, e foi o primeiro passo para a implantação do novo Parque. Esse processo foi iniciado na gestão do entáo prefeito Algemiro Manique Barreto (1973 - 1977), quando o aeroporto foi desativado, e completado nas gestóes de Altair Guidi (1977 - 1983 / 1989 - 1992), que tratou da construção do novo espaço.

A implantação do Parque Centenário, assim chamado em decorrência das comemoraçóes do centenário da fundação de Criciúma em 1980, ocupou cerca da metade da área correspondente ao antigo aeródromo, na porção mais próxima do centro da cidade (Figura 1). No lado oposto, nas proximidades do Bairro Pinheirinho, foi implantado um novo loteamento - o Loteamento Aeroporto, aprovado em lei com propósito de incrementar a arrecadação municipal (CRICIÚMA. Lei No 1.165, de 4 de Abril de 1975).

Figura 1: Do aeroporto ao Parque Centenário, em 1978

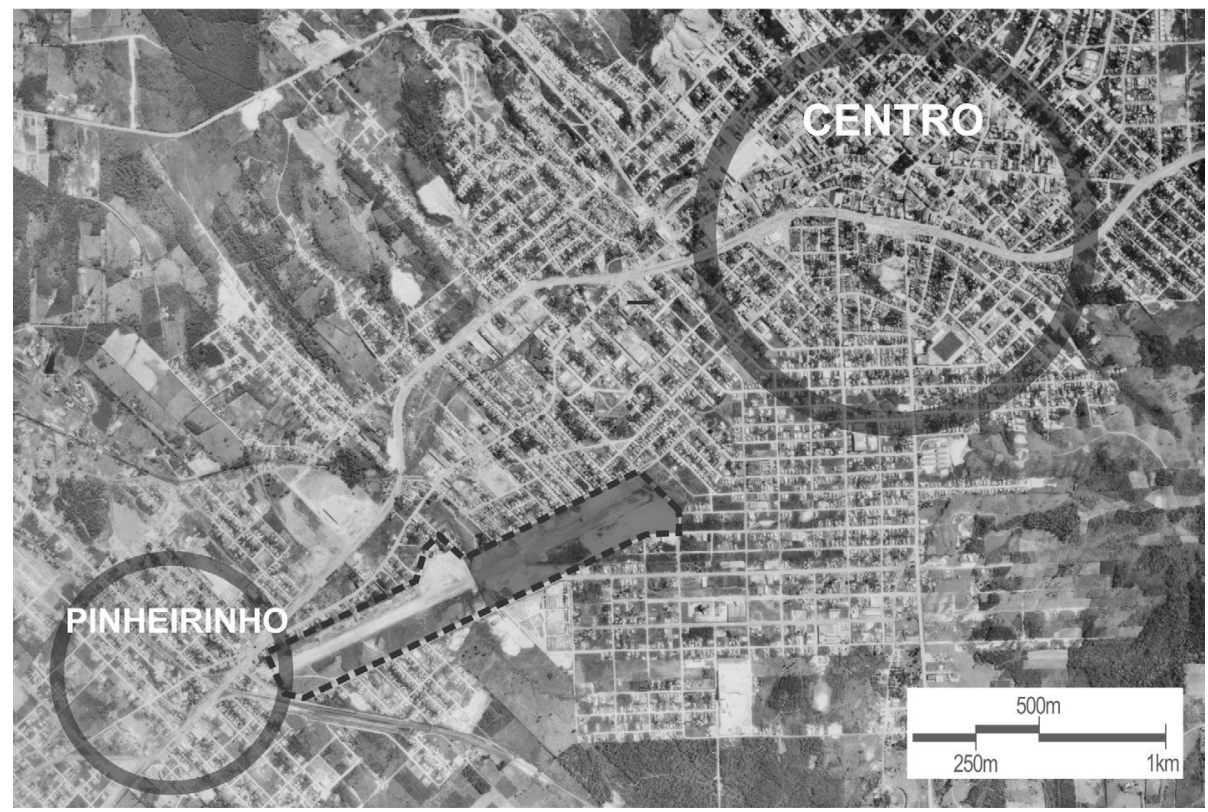

Fonte: Elaborado pelo autor com base em Prefeitura Municipal de Criciúma (1978).

A linha tracejada representa a área do Aeroporto Leoberto Leal, antigo aeródromo municipal; em seu interior, a porçáo preenchida em cinza corresponde à área posteriormente ocupada pelo Parque Centenário. Nos círculos, as demarcaçóes do Centro e do bairro Pinheirinho, uma subcentralidade da cidade. 
A intenção para o projeto era a implantação de um complexo arquitetônico de características majoritariamente cívicas. Foi construído após a realização de um concurso no qual participaram, entre outros arquitetos, Fernando Carneiro, responsável por importantes exemplares modernistas em Criciúma, e Manoel Coelho, autor da proposta escolhida, que tinha claras influências da escola moderna paulista, brutalista e contemporânea a sua época. Para o arquiteto, tratou-se de um dos mais importantes projetos de sua obra e o grande despontar de sua carreira; para a cidade, a mais significativa entre um conjunto de intervençôes públicas que, desde o fim dos anos 1960, transformavam estruturalmente a paisagem.

Figura 2: O Parque Centenário na década de 1980
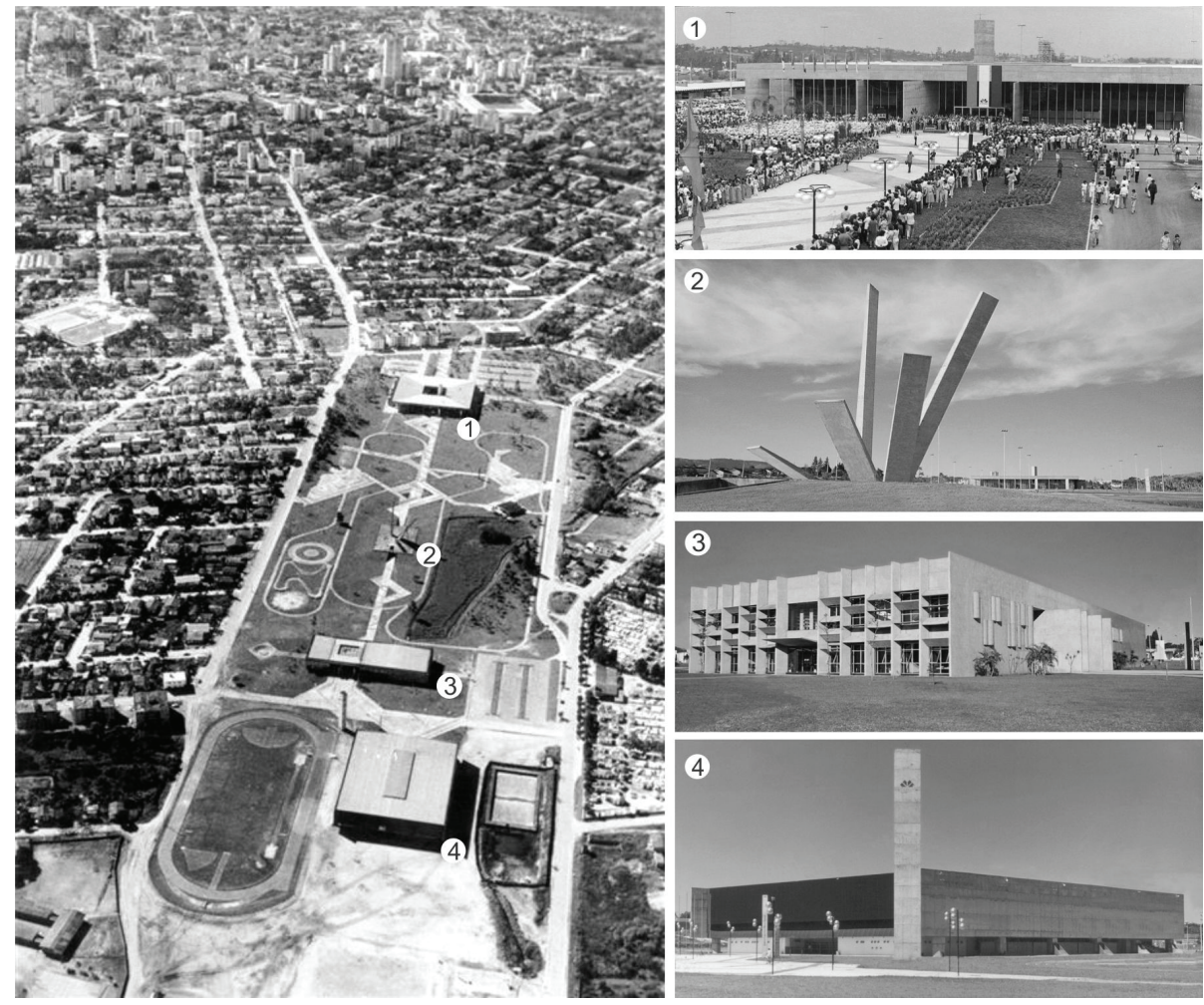

Fonte: Prefeitura Municipal de Criciúma; MCA.

Nota: 1 - Paço Municipal; 2 - Monumento às Etnias; 3 - Centro Cultural; 4 - Centro Esportivo.

Pela primeira vez a cidade conquistava espaços de política, cultura e esportes de grande porte, numa escala que a fazia destacar-se na produção arquitetônica de Santa Catarina. O terreno comprido e estreito da antiga pista aeroportuária possibilitava a implantaçáo de uma sequência de equipamentos que não se isolavam completamente da malha de ruas residenciais em seu entorno, ainda que estivessem soltos no lote (Figura 2). O Paço Municipal, o Memorial às etnias colonizadoras, o Centro Cultural - que abriga o Teatro Elias Angeloni - e o Centro Esportivo passaram a compor a paisagem limítrofe do centro e a projetar novos signos à urbe. Para seu arquiteto idealizador, são notáveis as influências dos conceitos do movimento moderno, evidentes quando "os edifícios são figuras arquitetônicas que se projetam sobre um fundo espacial cujos limites são o céu e o paisagismo" (COELHO, 2013, p. 52). Ainda assim, não se trata de "um (des)conjunto de obras isoladas, perdidas na solidão de um 
vasto lote vazio, como tantas vezes ocorreu nos projetos derivados da Carta de Atenas" (COELHO, 2013, p. 52). De fato, o parque não é formado por vazios aleatórios, mas por uma extensa área verde estruturada por um eixo longitudinal central, sobre o qual se distribui uma sequência de edificaçôes públicas alinhadas e com funçôes definidas - administração, contemplação, cultura e esporte. Os edifícios contornados por vazios definem morfologicamente uma configuraçáo modernista de quadra e valorizam sua monumentalidade horizontal.

O Parque Centenário foi a principal obra comemorativa ao centenário de fundação de Criciúma. As formas arquitetônicas ortogonais reportavam-se a símbolos municipais ou a fragmentos da história local, mas também permeavam a construção abstrata de um ponto de partida para um horizonte de progresso, para um futuro promissor, tấo importante para uma cidade de fortes valores desenvolvimentistas. Em busca de resgatar as raízes de Criciúma, e também de recontá-la de modo idealizado, reforçou-se o discurso étnico como nova marca cultural da cidade ${ }^{2}$, cujo maior símbolo era o Monumento às Etnias, construído ao centro do Parque. Ao expor suas recordações administrativas, o ex-prefeito Altair Guidi, com formação em Arquitetura e Urbanismo, assim declara:

Quando comemoramos o Centenário da fundação de Criciúma, nos anos oitenta do século passado, juntamente com a nossa equipe de governo, projetamos e implantamos o Parque Centenário. E o fizemos porque, assim como a grande maioria dos Criciumenses, estávamos convencidos de que era naquele local - no Parque Centenário - que o Criciumense, inspirando-se na sua história, projetaria o seu futuro (GUIDI, 2015, n.p.).

Junto com o Parque, consolidavam-se a cidade moderna, a "capital dos pisos e azulejos" e as etnias como marcas de Criciúma, disputando espaço com os imaginários historicamente construídos e relacionados à mineração de carvão (NASCIMENTO, 2012). Assim, na qualidade de principal obra pública de sua época e como respaldo a seu peso simbólico, mesclaram-se os novos signos da cultura local com os principais poderes políticos da cidade:

E, por isso, naquele local deveriam ser implantados os principais símbolos da nossa Cidade: $\mathrm{O}$ monumento que nos remete ao nosso maior patrimônio - as nossas etnias - bem como o símbolo da nossa Cultura, o grande Teatro, juntamente com o símbolo da nossa Soberania: as sedes dos Poderes Executivo e Legislativo. A sede da Câmara ainda não foi construída. Mas o projeto já está pronto e evidencia um edifício integrado ao ambiente histórico do Parque (GUIDI, 2015, n.p.).

As obras públicas da virada dos anos 1970 para a década de 1980 foram a apoteose da construção da cidade de características modernas. Espaços e edifícios públicos monumentais materializavam certos valores republicanos, implícitos nos discursos oficiais. O Paço Municipal construído em planta livre, sem quaisquer paredes, simbolizava o transparecer do trabalho realizado nas repartiçóes administrativas. Também inserido no Parque Centenário, o conjunto formado entre a "brutalidade" do concreto aparente, tapeçarias, obras de arte e o mobiliário modernista constituíase num sofisticado ambiente para o foyer do Teatro Elias Angeloni, no mesmo edifício que passou a abrigar uma biblioteca municipal e uma galeria de arte. Exemplos de
2 Registra-se, ao longo das décadas de 1960 e 1970, que elementos alusivos à mineração foram, aos poucos, retirados dos bairros centrais de Criciúma: o ramal ferroviário foi transferido para fora do perímetro urbano, e a estação de passageiros e o "Monumento aos Homens do Carvão" foram demolidos. 
3 Reitera-se que, para o setor ceramista, a alternativa encontrada para enfrentar a crise interna foi investir nas exportações. Para isso, visando à adaptação às exigências de preço e qualidade na concorrência internacional, incorporaram novas tecnologias de produção (ISOPPO, 2009). propostas arquitetônicas de vanguarda e de soluçóes técnicas eficientes, num momento em que se difundiam nas paisagens urbanas catarinenses os pastiches oitocentistas com feiçôes meramente turísticas, a exemplo do falso enxaimel nas cidades de colonização alemã no Vale do Itajaí.

"O principal acontecimento é a cidade em si, vivendo a primavera de um novo tempo que ela mesma soube semear". Esta frase, fixada em metal sobre a parede de concreto bruto no acesso principal do Paço Municipal, representa, em parte, a aclamação da conquista da "nova cidade", cultivada com erros e acertos no imaginário e nos discursos das elites locais desde os anos 1960. Com forte apelo cívico, os novos equipamentos públicos da Criciúma dos anos 1980 eram a abstração de um espaço para a cidadania, ainda que os conjuntos social e urbano continuassem marcados com todas as mazelas da exploração e da desigualdade.

\section{O FIM DE UM CICLO}

A partir da metade dos anos 1980, o Brasil seguiu para um quadro de forte recessão econômica, de desregulamentação de diversos setores produtivos e de recuo de políticas públicas em todas as áreas sociais, inclusive no que se refere à urbanização - observa-se, por exemplo, a retração de financiamentos habitacionais e uma menor autonomia do Estado para investir em grandes obras de infraestrutura. Simultaneamente, vivia-se um processo de abertura política após uma ditadura de duas décadas e discutia-se a organização do Estado democrático. Na questáo energética, pauta importante para a matriz econômica de Criciúma, foram as recorrentes portarias e resoluçôes, a partir de 1983, que reduziam os subsídios estatais ao setor carbonífero, até ser totalmente desregulamentado no ano de 1990, quando, abruptamente, grandes empresas decretam falência e milhares de operários são demitidos - registra-se, por exemplo, que os 13.735 postos de trabalho gerados pelo setor carbonífero de Criciúma em 1989 foram reduzidos para 4.632 em 1990 (SANTOS, 1995).

O esgotamento do modelo econômico intervencionista foi um duro golpe à viabilidade dos setores carbonífero e ceramista ${ }^{3}$, historicamente dependentes de incentivos fiscais ou de medidas de proteção ante a concorrência internacional. A economia local em colapso trouxe consigo passivos sociais violentos, que exigiram a construção de alternativas, porém não imunes à flexibilização das relaçôes trabalhistas, aos subempregos e ao empobrecimento doméstico. Por sua vez, o poder de atuação da administração pública municipal como agente direto da renovação do espaço urbano ficou comprometido diante da redução da arrecadação e do agravamento das vulnerabilidades sociais. Os novos arranjos socioeconômicos impunham limitaçôes aos investimentos públicos e, definitivamente, rompiam o processo de intervençôes modernistas iniciado na década de 1960, do qual o Parque Centenário era representativo.

Como retratos dinâmicos da história incessante, as paisagens conformam as interaçôes cotidianas, os ganhos e as perdas, o empobrecimento materializado das crises, as marcas do passado, as contradições dos ambientes urbanos. Na condição de espaço público, o Parque Centenário adentrou a década de 1990 em seu apogeu, mas já em iminente decadência enquanto a mais recente obra de um ciclo político-econômico esgotado. A cada gestão, acumulavam-se negligências técnicas, intervençóes controversas, descaracterizaçôes e descuidos com a manutenção, que se pressupunha periódica. Um 
quadro que não se restringia ao parque, mas também às demais obras construídas no mesmo período, que compartilhavam de semelhante linguagem estética e de situações equivalentes de deterioração. Tratava-se - e assim permanece - de uma característica comum das administraçôes públicas brasileiras, que é a desvalorização do espaço público já construído, o que condena as cidades à permanente escassez e a um movimento cíclico de novos projetos que nascem vulneráveis à ausência de continuidade. Suscetíveis aos interesses corporativos, as obras públicas assumem papel de objetos descartáveis a serem refeitos. Junto ao atraso das açôes de proteção patrimonial, configura-se aí um ciclo completo de desprendimento às paisagens históricas.

\section{A DECADÊNCIA DO PARQUE CENTENÁRIO}

Ao sujeitar os espaços públicos a pressóes fragmentadoras e ao residual dos orçamentos, as heranças que espacializaram as intençôes por uma cidade moderna na segunda metade do século passado têm sido, aos poucos, desconstruídas. As obras públicas que transformaram as estruturas da paisagem e representavam a chegada do "novo" hoje padecem da falta de zelo e de recentes movimentos substitutivos. No apogeu de sua época, o Parque Centenário foi concebido como idealização de uma imagem urbana, o cartão-postal de Criciúma e das administraçôes do período e, logo, uma das mais completas referências do modernismo como conjunto arquitetônico e paisagístico em Santa Catarina. Tal relevância, entretanto, não o isentou de perdas e descaracterizaçôes irreversíveis. Ao contrário, assimila em suas atuais condiçôes físico-ambientais todo o quadro de obsolescência recorrente em monumentos públicos do passado e em lugares construídos para atividades lúdicas de interação social. Os equipamentos institucionais foram expressivamente descaracterizados e expóem problemas estruturais de infiltração após décadas de falta de manutenção e comprometimento do sistema de drenagem do complexo. Nas áreas externas, as pichaçóes e sujeira acumuladas nas fachadas de concreto aparente misturam-se à destruição do calçamento de pedra portuguesa, ao assoreamento do lago previsto no projeto original e à falta de zelo paisagístico (Figura 3). No interior dos edifícios, sobram adaptaçóes mal elaboradas, situaçóes de materiais e instalaçôes prediais comprometidas e perda de objetos públicos de valor artístico, a exemplo das tapeçarias com o logotipo da cidade e dos móveis modernistas que compunham o foyer do Teatro Elias Angeloni, hoje danificados ou completamente perdidos pelas gestôes dos anos 1990 em diante. Nessa realidade, episódios lastimáveis, como as inundações na sala de apresentaçóes do Teatro a cada chuva torrencial, evidenciam o comprometimento dos sistemas de drenagem e vedação.

Nem mesmo o Paço Municipal Marcos Rovaris, a sede da prefeitura e, portanto, o epicentro político local, foi eximido do descaso. $\mathrm{O}$ tamanho das atuais administraçôes públicas é maior do que na década de 1980 e, somado às novas ferramentas de trabalho, tornou-se naturalmente necessária a adaptaçáo do edifício às demandas do presente. Entretanto, especialmente por sua condição de monumento urbano, não se justifica a ausência de manutenção periódica das instalaçôes prediais ou a recorrente perda de elementos e detalhes arquitetônicos que referenciam a originalidade da obra, a exemplo do mobiliário modernista e das tipografias em metal fixadas sobre o concreto. Para este caso, dois incêndios de grandes proporçôes, num intervalo de 
4 Os 5 painéis cerâmicos datam de 1995 e são de autoria de conjunta dos artistas visuais Gilberto Pergoraro, Jussara Guimarães e Vilmar Kastering. Atualmente, dadas as condições de hostilidade do ambiente e de deterioração das obras, discute-se a possibilidade de serem removidas do subsolo do Monumento às Etnias. poucos dias, dimensionam a tragédia pública da indiferença. $\mathrm{O}$ primeiro, ocorrido na madrugada do dia 27 de Maio de 2015, destruiu cerca de 25 a 30\% do prédio; o segundo, mais grave, aconteceu na tarde do dia 07 de Junho e consumiu aproximadamente 70\% do Paço (POSSEBON, 2015). Conforme perícia ligada à Polícia Civil de Santa Catarina, os incêndios foram provocados por sobrecarga na rede elétrica, agravada por nunca ter sido refeita desde inauguração do imóvel, em 1980. A rede elétrica em colapso, o forro caindo, o mobiliário original destruído, entre outras situaçôes visíveis a qualquer visitante, apenas indicavam o resultado de décadas de negligências cotidianas, que transpassaram diversas gestôes.

Finalmente, por se tratar de um ícone do conjunto projetado por Manoel Coelho, destaca-se o Monumento às Etnias, inaugurado em 1981 sob a pitoresca abstração que lembra uma mão brotando do solo - referência simbólica de trabalho e de conquistas - e homenageia as cinco supostas etnias colonizadoras da cidade (Figura 3). Em seu subsolo, onde funciona o Memorial Dino Gorini, encontram-se instalados desde 1995 cinco painéis artísticos feitos de cerâmica ${ }^{4}$, o principal produto industrial da fase modernista da cidade, que homenageiam as etnias às quais é dedicado o Monumento. Tanto o objeto arquitetônico quanto as obras de arte estão comprometidos pelas condiçóes agressivas de umidade do terreno, as quais nunca foram efetivamente resolvidas. A partir de 2005, o subsolo chegou a ser interditado - e esquecido - por não ter condiçôes mínimas de salubridade e segurança para uso; recentemente, com o estado de precariedade sendo divulgado na imprensa local, foi executada uma reforma emergencial, porém controversa e incompleta, na qual foram realizados serviços de limpeza, reinstalada a rede elétrica, mas também pintadas as paredes de concreto aparente. $\mathrm{O}$ aspecto de abandono amenizou-se, sem, no entanto, apresentar soluçóes definitivas para intervençóes inadequadas - por exemplo, o fechamento do sistema de iluminação zenital ao subsolo. Também permanecem sem resposta o problema das infiltraçôes e a situação de insegurança, que evidentemente têm relação com o conjunto do parque.

O acúmulo de décadas de descaso ao Parque Centenário representa custos de proporçôes possivelmente limitantes para que o município tenha condiçôes de viabilizar obras de infraestrutura e restauração necessárias. Não suficiente, ainda se acumulam situaçôes de fragmentação da dimensão original para a implantação de pátios de estacionamento e doação de fraçóes do terreno para a construçáo de sedes de entidades públicas, como a Ordem dos Advogados do Brasil (OAB) e a Associação dos Municípios da Região Carbonífera (AMREC) (Figura 3). Somada à leitura histórica e à contextualização política, a percepção de conjunto do Parque Centenário torna mais clara sua importância como um registro paisagístico da cidade moderna. Condená-lo ao abandono, que potencializa subdivisóes do conjunto e desgaste das estruturas, é um atentado ao patrimônio público, à história da cidade e ao próprio sentido de cidadania incorporada em suas formas e funções. 
Figura 3: Aspectos atuais: fragmentaçóes e esfacelamento do paisagismo original
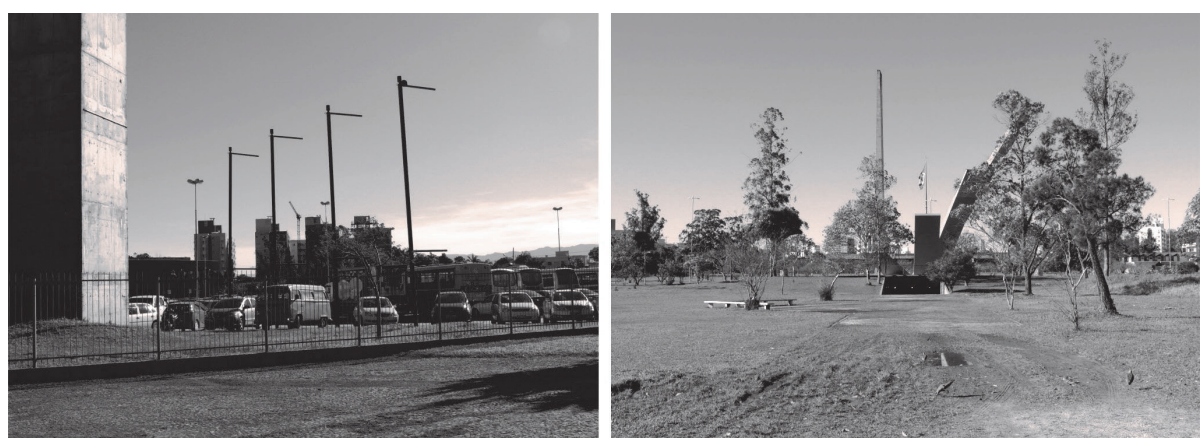

Fonte: Acervo do autor (2016).

Nota: Na primeira foto, um gradil demarcando um estacionamento no local; na segunda imagem, o esfacelamento do paisagismo original do parque, inclusive de seu eixo estruturador.

\section{POR NOVAS POSSIBILIDADES PARA O PARQUE CENTENÁRIO}

As limitaçóes das administraçôes públicas brasileiras para desempenhar experiências criativas por uma melhor qualificação dos espaços urbanos é uma situação, de certo modo, opressora. O nível de carências no país, que se reproduzem em Criciúma, faz com que os movimentos sociais urbanos, quando organizados, ainda se restrinjam a lutar por demandas que deveriam ser básicas: o tombamento de um ou outro imóvel histórico icônico e ameaçado, a manutenção de calçadas nos principais eixos viários, a revitalização de espaços públicos estruturadores. Sem garantia do elementar, consequentemente, não se dá continuidade a experiências de vanguarda do passado, que poderiam ser complementadas de modo coerente com novos debates, contextos e necessidades.

Até agora, o resgate do processo histórico do Parque Centenário e suas resultantes espaciais permearam uma ideia de conjunto. Faz-se necessário, porém, esforço por classificar e analisar seus aspectos fundamentais. A partir da valorização de suas partes, são apontadas, nos tópicos subsequentes, diretrizes para conciliá-lo com sua história e com seu papel de potencial articulador da estrutura urbana. Metas distintas, porém mutuamente complementares e sintonizadas em tempos diversos, imprescindíveis do envolvimento da população e de um comando público austero e transparente.

\section{O PARque CEnTENÁrio como patrimônio}

Ainda que a relevância patrimonial do Parque Centenário seja reconhecida, a absoluta insuficiência de políticas públicas de preservação em Criciúma - situação que se repete em cidades brasileiras com economia dinâmica e pouca tradição em açóes de preservação - fazem persistir condiçóes adversas de vulnerabilidade. A precária estrutura e a autonomia limitada de atuação do órgão municipal de patrimônio - o Serviço de Patrimônio Histórico, Artístico e Natural do Município (SPHAM) ${ }^{5}$, serviço atualmente vinculado à Fundação Cultural de Criciúma -, somadas ao nível de atraso no debate local e ao peso das pressóes imobiliárias nas legislações municipais,

5 SPHAM, criado pela le municipal № 2.063, de 1985 - a primeira lei de preservação patrimonial de Criciúma. 
praticamente anulam os esforços pela preservação dos conjuntos históricos remanescentes. A lei municipal de tombamentos vigente, atualmente em revisão, é completamente defasada e não reconhece contextos paisagísticos ou inserções mais amplas, nem mesmo quando, espacialmente, há a configuração explícita de um conjunto de relevância patrimonial. Para o Parque Centenário, desde 2011 estáo homologados os tombamentos das fachadas do Paço Municipal e do Centro Cultural, porém tomados em si, isolados do entorno, como se não fossem elementos de um único conjunto. Além das políticas municipais, é notável a ausência de quaisquer ações de preservação patrimonial a nível estadual, o que reforça o esquecimento e a vulnerabilidade dos bens históricos nas cidades catarinenses sem grandes vocaçóes turísticas.

$\mathrm{Na}$ condição de excepcionalidade, faz-se urgente, portanto, o envolvimento direto da Fundação Catarinense de Cultura - o órgão estadual de patrimônio histórico - como estratégia para preservar o Parque Centenário de outras descaracterizaçóes. Além de legitimar sua relevância patrimonial, tal reconhecimento poderia ampliar possibilidades políticas para a captação de recursos para projetos futuros.

\section{O Parque Centenário como espaço estruturador}

A escala monumental do Parque Centenário favoreceu sua condição de elemento estruturador da malha viária e das intençôes de expansão urbana. Admite-se, entretanto, que o vislumbre pela concepçáo de um conjunto relativamente distante do centro tradicional, e sem a devida articulação com as vias arteriais, também o tenham impedido de maior inserção ao tecido urbano -crítica comum às grandes obras do movimento moderno, que potencializava a sistematização autônoma de volumes abstratos, mas com certa dificuldade de interação com o entorno (MONTANER, 2009). Desse modo, o perímetro do Parque é ainda caracterizado por vazios ou áreas residenciais de baixa e média densidades, insuficientes para responder à utilização dos espaços livres e dos equipamentos culturais e esportivos.

Huet (1986/87, p. 86) defende a ideia de que um traçado "é sempre hierarquizado: hierarquia técnica, funcional, simbólica e monumental. Isto, portanto, deverá ser determinado por uma hierarquia institucional na mesma medida em que, por sua vez, determina o espaço monumental da cidade". A condição de monumentalidade, que pressupóe um equipamento público de abrangência municipal ou regional, deve ser acompanhada, portanto, de uma proporcional articulação com a cidade. Esta e outras condutas, que implicam numa concepção urbana de totalidade, poderiam dar embasamento às legislaçóes urbanísticas municipais, hoje empobrecidas por debates que se limitam a definir índices construtivos.

Uma leitura preliminar do Parque permite apontar diretrizes que potencializariam sua condição de estruturador dos sistemas urbanos. Primeiramente, a partir da compreensão de que "é pela continuidade da rede dos espaços públicos que a cidade vai tomando a sua forma” (HUET, 2001, p. 148), supóe-se que o atual grau de fragmentação admite que até mesmo articulaçôes elementares sejam propostas. Assim, sem desvincular-se das ruas, é possível a configuração de uma rede de áreas verdes e vazios urbanos - incluindo, por exemplo, a Praça Santa Bárbara e os vazios remanescentes do processo polinucleado de formação da cidade (Figura 5). Estes seriam pontos articuladores de um sistema de circulação requalificado, amparado por usos mais ou menos misturados, tipologias e densidades coerentes com atividades livres e com 
um desenho urbano humanizado, a serem considerados nos planos urbanísticos. Expóe-se, como exemplo, a Rua Visconde de Cairú (Figura 4), ligação direta do Parque Centenário com os bairros centrais mais adensados, e que reivindicam novos espaços públicos de lazer; valendo-se desta demanda, caberia a aplicação de uma concepção de desenho estimuladora da continuidade e da permanência, na qual poderiam ser incluídos alargamento de passeios, arborização, diversificação do nível térreo e, vinculada à dimensão da rua, a demarcação de ciclofaixas ou ciclovias planejadas em rede.

Figura 4: Inserção do Parque Centenário no espaço urbano de Criciúma

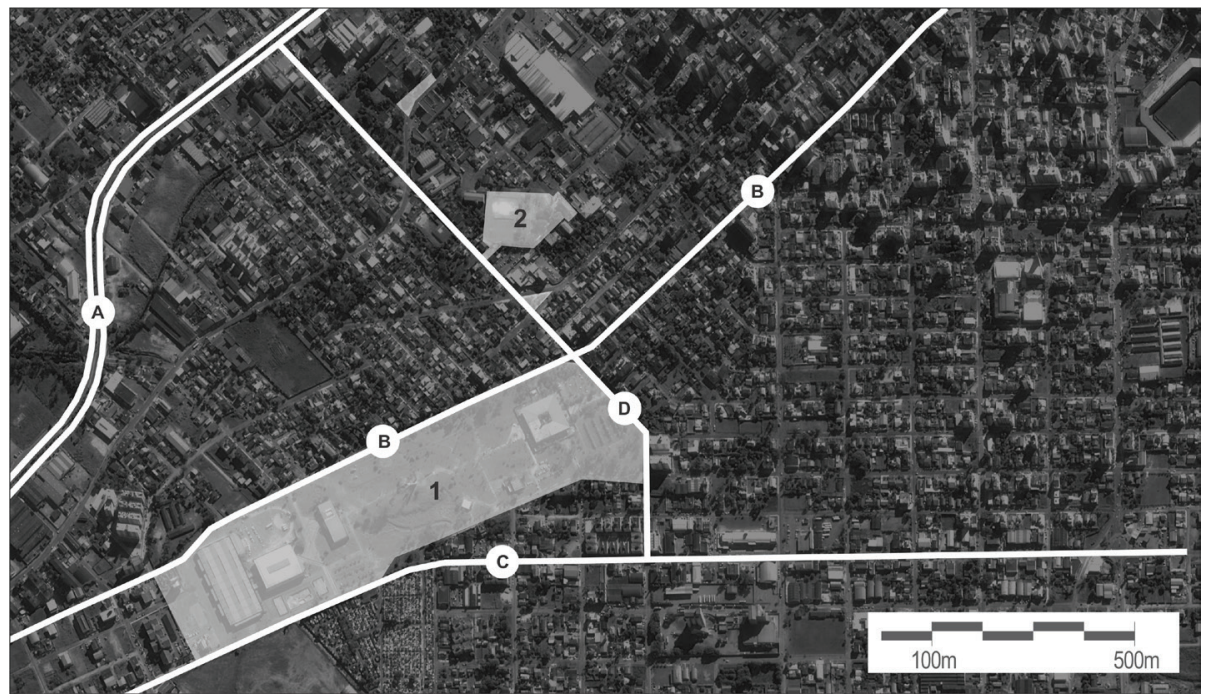

Fonte: Elaborado pelo autor com base em Google (2016).

Nota: 1 - Parque Centenário; 2 - Praça Santa Bárbara; A - Avenida Centenário; B - Rua Visconde de Cairú; C - Avenida Santos Dumont; D - Rua Domênico Sônego.

Junto com a imprescindível preservação do conjunto arquitetônico, as ações de planejamento e desenho urbanos contribuiriam para acentuar a articulação do Parque Centenário com as demais estruturas da cidade, estimulando novas apropriaçóes. Reconhece-se, contudo, que isto não é suficiente. É fundamental a reconstituição da dimensão cívica, talvez a mais expressiva do conjunto, e a mais representativa das demandas cidadās.

\section{O PARque Centenário como espaço cívico}

O mundo moderno do século XX legou aos sistemas contemporâneos preciosos conjuntos paisagísticos com funçóes majoritariamente cívicas; espaços generosos, contemplativos e soberanos, símbolos do Estado e antessala das manifestaçôes - culturais, esportivas, políticas - oficiais. Evidentemente, uma particularidade do Parque Centenário e, talvez, aquela que exija os maiores desafios. Para Berman (2007, p. 407), "ser moderno é experimentar a existência pessoal e social como um torvelinho, ver o mundo e a si próprio em perpétua desintegração e renovação, agitação e angústia, ambiguidade e contradição: é ser parte de um universo em que tudo que é sólido desmancha no ar". O mundo e a sociedade brasileira transformaram-se com vigor nas últimas décadas, e, para todos os novos valores cultivados, seja para o progresso ou 
para o atraso, formaram-se espaços e paisagens. O Parque Centenário foi concebido em um mundo - e numa cidade - que já não existe; entretanto, é oportuno questionar: qual será a dimensão cívica na sociedade brasileira contemporânea? Como construí-la? Como representá-la? Como inseri-la nas heranças modernas?

À escala de Criciúma, a ideia de civismo vinculada ao Parque Centenário consistia em uma representação do Estado e também em um legado de valor para a cidade. Seu reconhecimento como uma marca do criciumense decorre de sua relevância simbólica como patrimônio público e, portanto, de um espaço para o cultivo de uma ideia coletiva de cidadania. As condiçóes de abandono dos últimos anos têm sido um destrato aos valores arraigados ao lugar; e, portanto, um golpe à própria cidade. Por outro lado, "a gestação do novo, na história, dá-se, frequentemente, de modo quase imperceptível para os contemporâneos, já que suas sementes começam a se impor quando ainda o velho é quantitativamente dominante" (SANTOS, 2000, p. 69). No auge da indiferença, sob o acúmulo de décadas de descaso político, os incêndios no Paço Municipal trouxeram à tona seu significado como monumento a um futuro promissor e abstrato, embora nunca alcançado, que permeia imaginários da cidade e o pertencimento do criciumense. A imagem de sua destruiçấo foi um duro golpe às memórias e à própria cidade, mas também o estopim para uma ação no presente, mais ativa e cooperativa, zelosa pelo patrimônio público e exigente por respostas (Figura 5).

Figura 5: De um lado, as chamas tomando o Paço; do outro, a população em ação
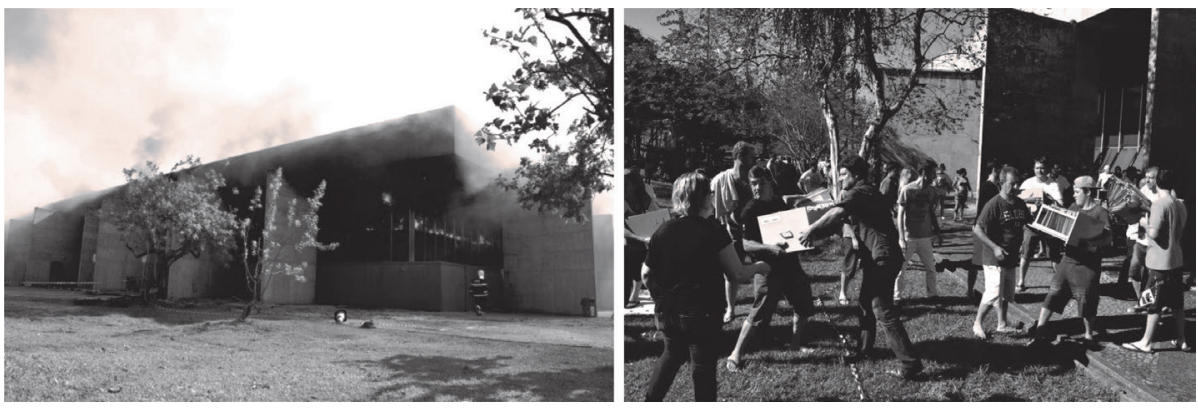

Fonte: Búrigo (2015a; 2015b).

Hoje, a administração municipal trabalha pela reconstrução do Paço, mas ainda como objeto isolado, sem ações efetivas de revitalização para os demais equipamentos e espaços livres. Inspirado na sugestão de Berman (2007) para Bronx - bairro de sua origem em Nova York -, e somada às propostas para a preservação do conjunto e sua reintegração à cidade, é preciso expor a real história do Parque Centenário: a transiçấo da economia extrativista para a diversificação industrial, o centenário da cidade e a construção de novos imaginários e símbolos, a ideia de progresso, a elegância e completude da arquitetura, sua decadência, depredaçóes e descaracterizaçóes, a tragédia dos recentes incêndios e quiçá uma revigoração com novos projetos. Imagens que sejam colaborativas para um resgate da civilidade moderna do passado, mas também inspiradoras para a construção de novos significados. Estas e outras ações apontam caminhos possíveis, mas só farão sentido com uma gradativa e permanente vinculação da população ao debate. $\mathrm{O}$ contrário é o vazio, a aridez de um parque condenado em uma cidade sem memória. 


\section{CONSIDERAÇÕES FINAIS}

Os acervos modernistas brasileiros sobrevivem em estágio de esfacelamento diante de políticas públicas que, quando não direcionadas a bens de origem colonial, ainda se concentram nos espaços icônicos das maiores cidades. Assim, sem grandes resistências, fragmenta-se o mosaico de paisagens que compóem uma totalidade nacional, o que se repete no contexto catarinense. $\mathrm{O}$ amesquinhamento relacionado a uma política social visionária espacializa-se, amplifica o caos urbano e empobrece a resplandescência de paisagens históricas. Nessa urbanização concebida aos pedaços, a partir de resíduos do passado sem adequada proteção patrimonial, insere-se o Parque Centenário, obra emblemática de Criciúma e da arquitetura moderna, mas já apequenado por sucessivas intervençôes incompatíveis. Faz-se urgente, portanto, a preservação do conjunto arquitetônico através da homologação de seu tombamento em nível estadual, além da implantação de medidas que busquem restaurar parte de suas características originais e integrá-lo a escalas mais amplas da cidade.

E assim as cidades caminham... Espaços que no passado permearam ideias de utopias, hoje padecem em situaçóes de extremo descaso; abandonados pela indiferença, fragmentados por limitaçôes técnicas de todos os tipos e açôes políticas medíocres. Em conjunto com a totalidade dos processos agressivos acumulados nas paisagens e no cotidiano vivido, configura-se uma crise urbana. Clama-se, então, ao papel do ativista, do urbanista, ou do "arquiteto rebelde" conforme Harvey (2012), que sirva como estímulo ao novo, ao equilíbrio ecológico e patrimonial, que permita a tradução das aspiraçôes políticas transformadoras dos que querem algo além da lógica vigente, mas que se ocultam ante o excesso de desafios. É estratégico, nesse contexto, tornar o planejamento urbano caricatura de debates e utopias contemporâneas, mas sem desvinculá-lo das demandas socioambientais reais. Considera Mongin (2009, p. 301) que "o roteiro de uma utopia urbana contemporânea, coletiva e preocupada com a existência de um lugar, não é uma ficção ou uma promessa piedosa”; pelo contrário, é real e tem-se manifestado.

A gênese da cidade é a produção social repleta de contradições. Numa concepção lefebvriana, o direito à cidade "só pode ser formulado como direito à vida urbana, transformada, renovada" (LEFEBVRE, 2001, p. 118). Mais ainda, inclui o direito à obra, que se refere à participaçáo popular direta na vida política e comunitária. Apesar dos dilemas, os últimos anos também têm mostrado situaçóes de resistências setorizadas, de açóes coletivas, de procura pela rua como espaço da prática política. O empenho da população comum em tentar salvar documentos e móveis públicos enquanto o Paço Municipal era tomado pelas chamas e, com mais frequência, as açôes de coletivos que visam a ocupar o Parque Centenário com atividades de lazer, são representativos de que há quem se importe, e não são poucos. Esse aprendizado da cidadania, paradoxo de momentos e ambientes inesperados, é o único caminho para a construção do novo, conciliado com indivíduos livres e cidades com memória. E, como retrato vivo de Criciúma, que o Parque Centenário seja representativo do encontro da cidade com o tão sonhado futuro promissor.
6 Em Espaços de Esperança Harvey (2012) faz do arquiteto uma metáfora para a corporificação do ser político, praticante, especulativo, dotado de certas capacidades passíveis de serem usadas para transformar o mundo.

Gustavo Rogério De Lucca é Arquiteto e Urbanista pela Universidade do Extremo Sul Catarinense; mestre em Urbanismo, História e Arquitetura da Cidade e doutorando no Programa de Pós-Graduação em Geografia pela Universidade Federal de Santa Catarina (UFSC); Professor do Curso de Arquitetura e Urbanismo na Universidade do Extremo Sul Catarinense.

E-mail: arqgustavodelucca@ gmail.com

Margareth de Castro Afeche Pimenta é Arquiteta e Urbanista pela Faculdade de Arquitetura e Urbanismo da Universidade de São Paulo - USP; mestre pelo Instituto Alberto Luiz Coimbra de Pós-Graduação e Pesquisa de Engenharia, da Universidade Federal do Rio de Janeiro - UFRJ; doutora pela Universidade de Paris IV - Sorbonne; Professora do Departamento de Arquitetura e Urbanismo e da Pós-Graduação em Geografia da Universidade Federal de Santa Catarina.

E-mails: afeche@arq.ufsc. br ; pimenta.margareth@ gmail.com

Artigo recebido em 12 de dezembro de 2016 e aprovado para publicação em 27 de maio de 2017 


\section{REFERÊNCIAS}

BERMAN, M. Tudo que é sólido desmancha no ar: a aventura da modernidade. São Paulo: Companhia das Letras, 2007.

BÚRIGO, D. 2015a. Disponível em: <http://ricmais.com.br/sc/wp-content/uploads/2015/06/ DNLBURIGO_segundo-incendio-na-prefeitura-9-620x400.jpg>. Acesso em: 01 ago. 2016.

2015b. Disponível em: <http://dc.clicrbs.com.br/sc/noticias/noticia/2015/06/ prefeitura-de-criciuma-define-locais-em-que-servicos-vao-funcionar-apos-incendio-4777366.html>. Acesso em: 01 ago. 2016.

CASTELLS, M. A questão urbana. 3 ed. Rio de Janeiro: Paz e Terra, 1983.

COELHO, M. (Org.). Manoel Coelho: arquitetura e design. Curitiba: Manoel Coelho Arquitetura \& Design Ltda., 2013.

CRICIÚMA. Lei n. 947, de 11 de abril de 1973. Dispóe sobre o Plano Diretor. Lex: Disponível em: <https://leismunicipais.com.br/a1/sc/c/criciuma/lei-ordinaria/1973/94/947/ lei-ordinaria-n-947-1973-dispoe-sobre-o-plano-diretor>. Acesso em: 25 jul. 2017.

Lei n. 1.165, de 4 de Abril de 1975. Autoriza loteamento de área do atual Aeroporto Municipal. Lex: Disponível em: <https:/leismunicipais.com.br/a1/sc/c/criciuma/ lei-ordinaria/1975/117/1165/lei-ordinaria-n-1165-1975-autoriza-loteamento-area-do-atual-aeroporto-municipal?q=Autoriza $\% 20$ loteamento $\% 20 \mathrm{de} \% 20 \% \mathrm{E} 1 \mathrm{rea} \% 20 \mathrm{do} \% 20$ atual\%20Aeroporto\%20Municipal> Acesso em: 25 jul. 2017.

GUIDI, A. 8 jun. 2015. Disponível em: <https:/www.facebook.com/photo.php?fbi$\mathrm{d}=891037454285906 \&$ set $=$ pb.100001389803865.=2207520000-1486129280..\&type3\&theater> Acesso em: 25 jul. 2017

HARVEY, D. Espaços de Esperança. 5. ed. São Paulo: Ediçóes Loyola, 2012.

HUET, B. A cidade como espaço habitável: alternativas à Carta de Atenas. Revista Arquitetura e Urbanismo, v. 2, n. 9, p. 82-87, dez. 86/jan. 87. Disponível em: <http://www.fec. unicamp.br/ $\sim$ paulobruna/seminario1.pdf $>$. Acesso em: 25 jul. 2017.

. Espaços públicos, espaços residuais. In: Os centros das metrópoles: reflexões e propostas para a cidade democrática do Século XXI. São Paulo: Associação Viva o Centro, 2001. p. 147-151

INSTITUTO BRASILEIRO DE GEOGRAFIA E ESTATÍSTICA. Criciúma. Cidades@. Disponível em: <http://cidades.ibge.gov.br/xtras/perfil.php?codmun=420460>. Acesso em: 25 jul. 2017.

ISOPPO, K. K. V. Gênese e evolução da indústria cerâmica na região de Criciúma - SC. 2009. 243 f. Dissertação (Mestrado em Geografia) - Centro de Filosofia e Ciências Humanas, Universidade Federal de Santa Catarina, Florianópolis, 2009.

LEFEBVRE, H. O direito à cidade. São Paulo: Centauro, 2001.

MACEDO, S. S.; SAKATA, F. G. Parques urbanos no Brasil. 2 ed. São Paulo: Ed. USP, 2003.

MCA. Disponível em: <http://www.mcacoelho.com.br/?page_id=1357> Acesso em: 25 jul. 2017.

MONGIN, O. A condição urbana: a cidade na era da globalização. São Paulo: Estação Liberdade, 2009.

MONTANER, J. M. Sistemas arquitetônicos contemporâneos. Barcelona: Editorial Gustavo Gili, 2009.

NASCIMENTO, D. Faces da urbe: Processo identitário e transformaçóes urbanas em Criciúma/SC (1945-1980). Criciúma: EDIUNESC, 2012.

POSSEBON, D. Retrospectiva: Incêndios no Paço Municipal marcam ano difícil para gestão pública. Portal Clicatribuna, Criciúma, 22 dez. 2015. Disponível em: <http://www. 
clicatribuna.com/noticia/politica/retrospectiva-incendios-no-paco-municipal-marcam -ano-dificil-para-gestao-publica-15935>. Acesso em: 25 jul. 2017.

PREFEITURA MUNICIPAL DE CRICIÚMA. 1978. Disponível em: <http://www. criciuma.sc.gov.br/site/arquivo_historico/917.jpg>. Acesso em: 25 jul. 2017.

SANTOS, M. Por uma outra Globalização. São Paulo: Ed. USP, 2000.

Espaço e Método. 5 ed. São Paulo: Ed. USP, 2012.

O Espaço do Cidadão. 7 ed. São Paulo: Ed. USP, 2014.

SANTOS, M. A. Crescimento e crise na Região Sul de Santa Catarina. 1995. 186 f. Dissertação (Mestrado em Geografia) - Centro de Filosofia e Ciências Humanas, Universidade Federal de Santa Catarina, Florianópolis, 1995. 